\title{
Protective effects of astragaloside IV on IL-8-treated diaphragmatic muscle cells
}

\author{
LI WANG* ${ }^{*}$,WEI GU* ${ }^{*}$ YING SHI, YUBAO CHEN and YAN TAN \\ Department of Respiratory Medicine, Nanjing First Hospital, Nanjing Medical University, \\ Nanjing, Jiangsu 210006, P.R. China
}

Received July 21, 2017; Accepted September 12, 2018

DOI: $10.3892 /$ etm.2018.6940

\begin{abstract}
The diaphragmatic fatigue that results from airflow obstruction is associated with the severe morbidity of patients with chronic obstructive pulmonary disease. Astragaloside IV (AS-IV) has antioxidant, anti-apoptotic and anti-inflammatory activities in various cell types. The present study aimed to evaluate the protective effects of AS-IV in diaphragmatic muscle cells. Diaphragmatic muscle cells extracted from neonatal rats were treated with a series of AS-IV concentrations $(5,10$ or $20 \mathrm{mg} / \mathrm{l}$ ) and the AKT inhibitor GSK690693 in the presence of interleukin-8 (IL-8). Cell proliferation and AKT phosphorylation were measured using Cell Counting Kit-8 and western blot assays, respectively. Cell apoptosis and reactive oxygen species (ROS) production were evaluated using flow cytometric analysis. Caspase activity and concentrations of proinflammatory factors (tumor necrosis factor- $\alpha$, IL- 6 and IL-8) were assessed using a caspase colorimetric assay and ELISA, respectively. IL-8 treatment resulted in decreased rates of cell proliferation and increased rates of AKT phosphorylation, cell apoptosis, caspase 3/9 activity, ROS production and proinflammatory factor production. AS-IV and GSK690693 treatment reversed the effects of IL-8. The effects of AS-IV were dose-dependent. The present results suggested that AS-IV is a candidate for the treatment of diaphragmatic fatigue due to its antioxidant, anti-apoptotic and anti-inflammatory activity.
\end{abstract}

\section{Introduction}

Chronic obstructive pulmonary disease (COPD) has become a global public health problem due to the increasing prevalence and mortality associated with this condition (1). Chronic

Correspondence to: Dr Yan Tan, Department of Respiratory Medicine, Nanjing First Hospital, Nanjing Medical University, 68 Changle Road, Nanjing, Jiangsu 210006, P.R. China

E-mail:nfhtan@163.com

*Contributed equally

Key words: astragaloside IV, diaphragmatic fatigue, oxidative stress, AKT, interleukin-8 inflammation, oxidant/antioxidant imbalance and pulmonary cell apoptosis are involved in the pathogenesis of COPD (2-4). Patients with COPD suffer from an increased load on the aspiratory muscles, particularly the diaphragm, due to airflow obstruction $(5,6)$. Repetitive stimulation of the diaphragm results in overexpression of reactive oxygen species (ROS) in muscle fibers, oxidative stress and accelerated development of fatigue (7). Cytokines [e.g., tumor necrosis factor- $\alpha$ (TNF- $\alpha$ ) and interleukin-8 (IL-8)] have important roles in the pathogenesis of COPD (8). AKT is an intracellular serine/threonine protein kinase activated by different cytokines (e.g., TNF- $\alpha$ ). AKT is a central regulator of molecular pathways implicated in the pathogenesis of COPD. Compounds targeting AKT are used for the treatment of COPD (9).

Astragaloside IV (AS-IV) is extracted from Astragalus membranaceus, which is a herb used in Traditional Chinese Medicine as a therapeutic. It is used for the treatment of a variety of diseases due to its anti-oxidant, anti-apoptotic, anti-cancer and neuro-protective functions (10-16). Attenuated unilateral ureteral obstruction results from transforming growth factor- $\beta$ (TGF- $\beta$ )-induced cell apoptosis in renal tubules, which may be inhibited by AS-IV (17). AS-IV has been reported to protect neuronal cells from the neurotoxic effects of the 1-methyl-4-phenylpyridnium ion via the inhibition of reactive oxygen species (ROS) production and the pro-apoptotic pathway mediated by B-cell lymphoma 2-assocated X protein (18). AS-IV was also demonstrated to activate the AKT pathway in human umbilical vein endothelial cells and cardiomyocytes $(19,20)$.

The protective functions of AS-IV in patients with COPD have remained to be demonstrated. The aim of the present study was to investigate the anti-apoptotic, antioxidant and anti-inflammatory activities of AS-IV in IL-8-treated rat diaphragmatic muscle cells and to examine the possible mechanisms underlying the responses.

\section{Materials and methods}

Preparation of diaphragmatic muscle cells. Primary diaphragmatic muscle cell were prepared as previously described (21). The study was approved by the ethics committee of Nanjing Medical University (Nanjing, China). Diaphragm muscle strips were excised from 2-week-old rats, minced and digested with $0.2 \%$ collagenase IV (Sigma-Aldrich; Merck KGaA, 
Darmstadt, Germany) at $37^{\circ} \mathrm{C}$ for $60 \mathrm{~min}$. After washing with Dulbecco's Modified Eagle's medium (DMEM; Hyclone; GE Healthcare, Little Chalfont, UK), the cells were collected by centrifugation at $800 \mathrm{x}$ g for $5 \mathrm{~min}$ at room temperature. They were then incubated in DMEM containing $10 \%$ fetal bovine serum (FBS; Gibco; Thermo Fisher Scientific, Inc., Waltham, MA, USA) at $37^{\circ} \mathrm{C}$ in a humidified atmosphere containing $5 \%$ $\mathrm{CO}_{2}$.

Cell Counting Kit-8 (CCK-8) assay. Trypsinized diaphragmatic muscle cells were diluted to $3 \times 10^{4}$ cells $/ \mathrm{ml}$. Of this cell suspension, $100 \mu \mathrm{l}$ were then seeded into each well of 96 -well plates, which were incubated at $37^{\circ} \mathrm{C}$ for $12 \mathrm{~h}$. To determine the appropriate dose of IL- 8 , the cells were treated with one of four concentrations of IL-8 $(10,20,50$ or $100 \mathrm{ng} / \mathrm{ml}$; Sigma-Aldrich; Merck KGaA), while untreated cells served as controls.

To investigate the effects of AS-IV, cells were treated with $50 \mathrm{ng} / \mathrm{ml} \mathrm{IL-8}$ plus DMSO (the final concentration of which did not exceed $0.1 \%$ v/v; Sigma-Aldrich; Merck KGaA) or AS-IV $(2.5,5,10,20,40$ or $80 \mathrm{mg} / \mathrm{l}$; Aladdin, Shanghai, China). At 0, 24 or $48 \mathrm{~h}$ after treatment, the medium in each well was replaced with $100 \mu 1$ DMEM containing 10\% CCK-8 reagent (Dojindo Biochemicals, Kumamoto, Japan). The optical density (OD) was measured at a wavelength of $450 \mathrm{~nm}$ on a microplate reader and used to evaluate cell proliferation.

Cell apoptosis assay. Cultured cells were treated with $50 \mathrm{ng} / \mathrm{ml}$ IL-8 plus DMSO, AS-IV (5, 10 or $20 \mathrm{mg} / \mathrm{l}$ ) or $10 \mu \mathrm{M}$ GSK690693 (Selleck, Houston, TX, USA) for $48 \mathrm{~h}$ and then collected for annexin V-fluorescein isothiocyanate (FITC)/propidium iodide (PI) staining with an apoptosis detection kit (BD Biosciences, San Jose, CA, USA). The stained cells were detected using a flow cytometer (BD Biosciences).

Measurement of caspase-3 and caspase-9 activities. The activities of caspase- 3 and caspase- 9 were measured using a caspase colorimetric assay kit (Kengen Biotechnologies, Nanjing, China) following the manufacturer's protocol. In brief, treated cells were lysed using $100 \mu \mathrm{l}$ pre-cooled lysis buffer provided with the kit. The supernatant was collected by centrifugation at $14,000 \mathrm{xg}$ for $15 \mathrm{~min}$ at $4^{\circ} \mathrm{C}$. The protein concentration of the collected supernatant was determined using the Bradford method. Each $50 \mu \mathrm{l}$ of supernatant was mixed with $50 \mu 12 \mathrm{X}$ reaction buffer containing $5 \mu \mathrm{l}$ caspase substrate and $0.5 \mu \mathrm{l}$ dithiothreitol, followed by incubation at $37^{\circ} \mathrm{C}$ for $4 \mathrm{~h}$. Caspase activity was detected using a microplate reader with measurement of the OD at a wavelength of $400 \mathrm{~nm}$. The values for the Control group (cells without any treatment) were set as 1.0, and results were expressed as the ratio of the treatment vs. the Control group values.

Measurement of ROS. Treated cells were digested and resuspended with $10 \mathrm{mM}$ dichlorofluorescein diacetate (Beyotime Institute of Biotechnology, Shanghai, China) in DMEM for $20 \mathrm{~min}$ in the dark at $37^{\circ} \mathrm{C}$. Flow cytometry was used to detect ROS.

ELISA. Concentrations of IL-6 (cat. no. HM10205), IL-8 (cat. no. HM10222) and TNF- $\alpha$ (cat. no. HM10001) in treated diaphragmatic muscle cells were measured using ELISA kits (Bio-swap, Shanghai, China) following the manufacturer's protocol. The absorbance was detected at a wavelength of $450 \mathrm{~nm}$ and the concentrations of IL-6, IL-8, and TNF- $\alpha$ were calculated based on a standard curve.

Western blot analysis. Treated cells were lysed using radioimmunoprecipitation assay lysis buffer (Solarbio, Shanghai, China) and a protease inhibitor cocktail (Sigma-Aldrich; Merck KGaA). They were centrifuged at $12,000 \times$ g at $4^{\circ} \mathrm{C}$ for $15 \mathrm{~min}$. The supernatant was collected and the proteins were quantified using a bicinchoninic acid protein quantification kit (Thermo Fisher Scientific, Inc.). Equal amounts of total protein $(30 \mathrm{mg}$ ) were separated by $10 \%$ SDS-PAGE and transferred to nitrocellulose membranes (EMD Millipore, Billerica, MA, USA). The membranes were blocked using $5 \%$ skimmed milk at room temperature for $1 \mathrm{~h}$ and were then incubated with antibodies against AKT (cat. no. 9272; 1:1,000; Cell Signaling Technology, Inc., Danvers, MA, USA), p-AKT (cat. no. 9271; 1:1,000; Cell Signaling Technology, Inc.), and GAPDH (cat. no. 5174; 1:2,000; Cell Signaling Technology, Inc.) followed by incubation with goat anti-mouse (cat. no. A0216, 1:1,000) or anti-rabbit (cat. no. A0208; 1:1,000) secondary antibodies (Beyotime Institute of Biotechnology). Blots were visualized using enhanced chemiluminescence (Thermo Fisher Scientific, Inc.) and using the Tanon-5200 Image Analyzer (Tanon Science and Technology, Co., Ltd., Shanghai, China). The protein bands were semi-quantified using Image J software (version 1.71; National Institutes of Health, Bethesda, MD, USA).

Statistical analysis. Values are expressed as the mean \pm standard deviation. Differences between groups were analyzed using one-way analysis of variance followed by Tukey's post-hoc test. GraphPad Prism 6.0 software (GraphPad, Inc., La Jolla, CA, USA) was used to summarize and analyze the data. $\mathrm{P}<0.05$ was considered to indicate a statistically significant difference.

\section{Results}

AS-IV attenuates the anti-proliferative effects of IL-8 on primary diaphragmatic muscle cells. To determine the appropriate dose of IL-8, primary diaphragmatic muscle cells were incubated with 0 (Control), 10, 20, 50 or $100 \mathrm{ng} / \mathrm{ml} \mathrm{IL-8} \mathrm{for}$ 0,24 and $48 \mathrm{~h}$. The results of the CCK- 8 assay indicated that IL-8 significantly decreased the cell proliferation after 24 and $48 \mathrm{~h}$ of treatment in a dose-dependent manner (Fig. 1A). The $50 \mathrm{ng} / \mathrm{ml}$ concentration had effects similar to the $100 \mathrm{ng} / \mathrm{ml}$ concentration. Thus, $50 \mathrm{ng} / \mathrm{ml}$ was selected for the subsequent experiments.

The effects of AS-IV on diaphragmatic muscle cell proliferation were then assessed. AS-IV $(10,20,40$ and $80 \mathrm{mg} / \mathrm{ml})$ suppressed the anti-proliferative effects of IL-8 $(50 \mathrm{ng} / \mathrm{ml})$ on primary diaphragmatic muscle cells after 24 and $48 \mathrm{~h}$ of treatment (Fig. 1B). AS-IV (5 mg/l) also attenuated the anti-proliferative effects of IL-8 after $48 \mathrm{~h}$ of treatment. The $20 \mathrm{mg} / \mathrm{l}$ concentration had similar effects to those of the 40 and $80 \mathrm{mg} / \mathrm{l}$ concentrations. Thus, three concentrations of $\operatorname{AS}-I V(5,10$ and $20 \mathrm{mg} / \mathrm{l})$ were selected for the subsequent experiments. 

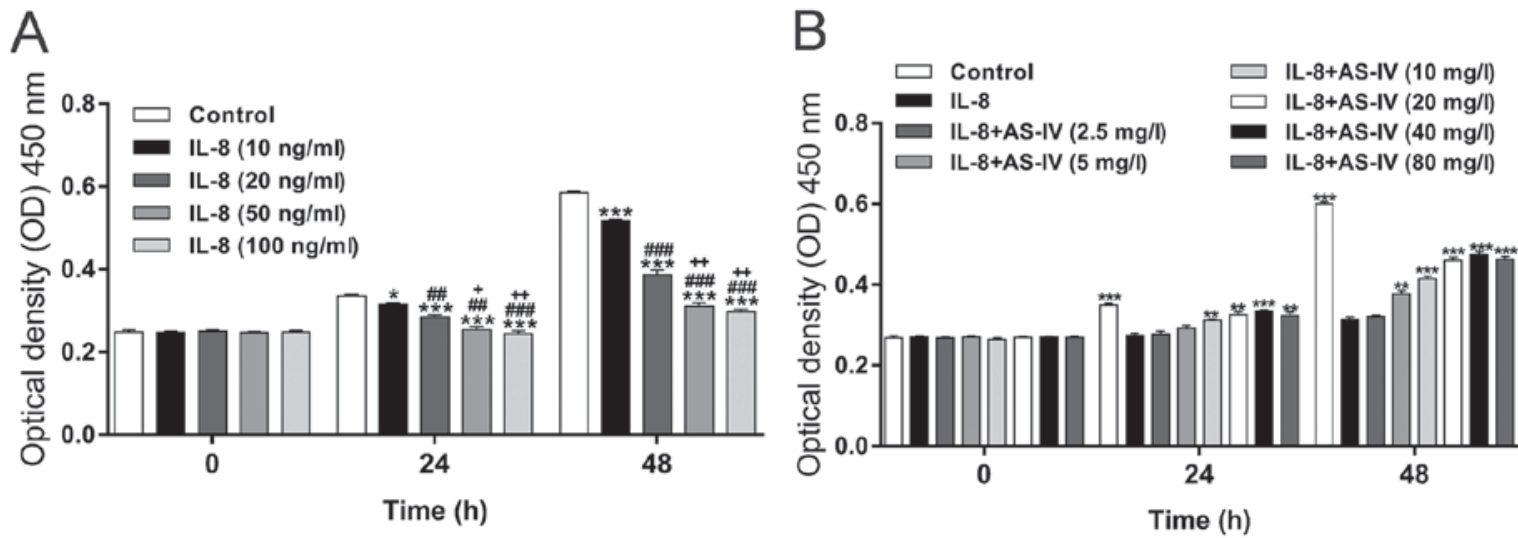

Figure 1. Cell proliferation was evaluated using a CCK-8. (A) Diaphragmatic muscle cells extracted from 2-week-old rats were treated with one of four concentrations of IL-8. At 0, 24 and $48 \mathrm{~h}$ after treatment, cell proliferation was measured using a CCK-8. (B) Diaphragmatic muscle cells were treated with $50 \mathrm{ng} / \mathrm{ml} \mathrm{IL}-8$ plus vehicle or various concentrations of AS-IV $(2.5,5,10,20,40$ or $80 \mathrm{mg} / \mathrm{l})$. Cell proliferation was analyzed using a CCK-8 assay. "P<0.05, ${ }^{* *} \mathrm{P}<0.01,{ }^{* * *} \mathrm{P}<0.001$, vs. Control; ${ }^{\# \#} \mathrm{P}<0.01,{ }^{\# \# "} \mathrm{P}<0.001$, vs. $10 \mathrm{ng} / \mathrm{ml} \mathrm{IL}-8 ;{ }^{+} \mathrm{P}<0.05,{ }^{++} \mathrm{P}<0.01$, vs. $20 \mathrm{ng} / \mathrm{ml}$ IL-8. CCK, Cell Counting Kit; IL, interleukin; OD, optical density; AS-IV, astragaloside IV.
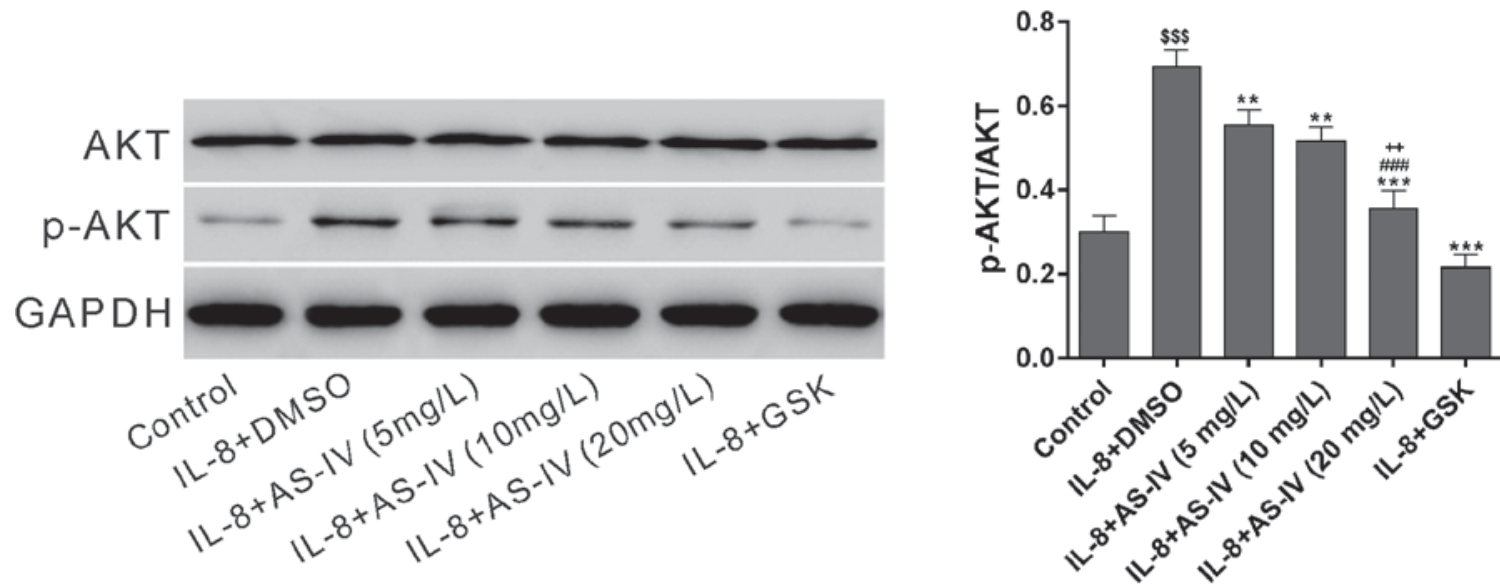

Figure 2. AS-IV blocked the AKT signaling pathway. Diaphragmatic muscle cells were treated with $50 \mathrm{ng} / \mathrm{ml}$ IL-8 plus vehicle (DMSO), AS-IV (5, 10 or $20 \mathrm{mg} / \mathrm{l}$ ), or $10 \mu \mathrm{M}$ GSK690693 for $48 \mathrm{~h}$. The concentrations of p-AKT and AKT were detected using a western blot assay. ${ }^{\$ \$} \mathrm{P}<0.001 \mathrm{vs}$. Control; ${ }^{* *} \mathrm{P}<0.01$, ${ }_{* * * * *} \mathrm{P}<0.001$, vs. IL-8 plus DMSO; ${ }^{\# \# \#} \mathrm{P}<0.001$, vs. IL-8 plus $5 \mathrm{mg} / 1$ AS-IV; ${ }^{++} \mathrm{P}<0.01$, vs. IL-8 plus $10 \mathrm{mg} / 1 \mathrm{AS}-\mathrm{IV}$. IL, interleukin; p-AKT, phosphorylated AKT; AS-IV, astragaloside IV; DMSO, dimethyl sulfoxide; GSK, GSK690693.

AS-IV blocks the AKT signaling pathway. AKT is a central regulator of molecular pathways implicated in COPD pathogenesis (9). To explore the effects of AS-IV on AKT signaling, primary diaphragmatic muscle cells were incubated with a series of AS-IV concentrations $(5,10$ or $20 \mathrm{mg} / \mathrm{l})$ and IL-8 (50 $\mathrm{ng} / \mathrm{ml})$ for $48 \mathrm{~h}$. Cells treated with IL-8 plus $10 \mu \mathrm{M}$ GSK690693 (an AKT inhibitor) were used as a positive control, while cells treated with IL-8 plus DMSO were used as a negative control. The total and phosphorylated AKT were detected using western blot analysis. The results indicated that phosphorylation of AKT was induced by IL-8 (Fig. 2). AS-IV and GSK significantly suppressed the induction effects of IL-8 on AKT phosphorylation. However, the levels of AKT were not affected by the different experimental conditions.

AS-IV attenuates cell apoptosis induced by IL-8. To investigate the effects of AS-IV on cell apoptosis, cells were double-labelled with annexin V-FITC/PI and subjected to flow cytometric analysis [Fig. 3A; lower right quadrant (Annexin $\mathrm{V}^{+} \mathrm{PI}$ ) indicates apoptotic cells]. A significant increase in the apoptotic rate compared with that in the Control group was observed in the IL-8 plus DMSO-treated group. The results indicated that AS-IV attenuated IL-8-induced cell apoptosis in a dose-dependent manner. GSK690693 had similar effects to those of AS-IV. The caspase- 3 and caspase- 9 activities measured using biochemical analysis were consistent with the results of the flow cytometric analysis (Fig. 3B). Overall, it was indicated that AS-IV had an anti-apoptotic effect on IL-8-treated diaphragmatic muscle cells.

Effect of AS-IV on IL-8-induced ROS production. ROS production was determined after $48 \mathrm{~h}$ of treatment with IL-8. IL-8 induced ROS production, which was significantly suppressed by GSK690693. Furthermore, AS-IV had a dose-dependent inhibitory effect on IL-8-induced ROS production (Fig. 4). 
A
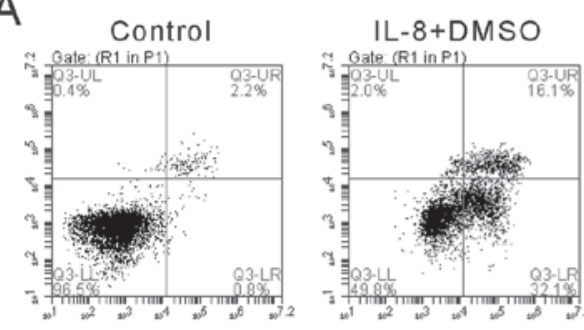

IL-8+AS-IV(10mg/L) IL-8+AS-IV(20mg/L)
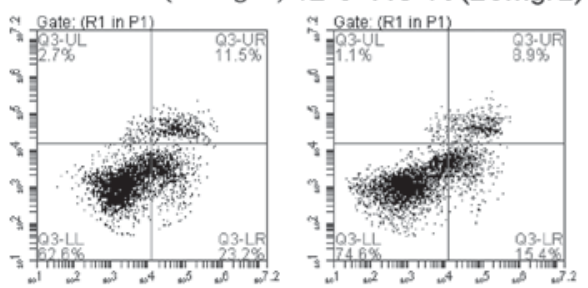

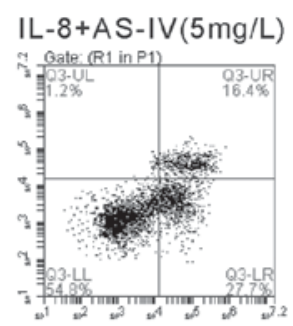

IL-8+GSK
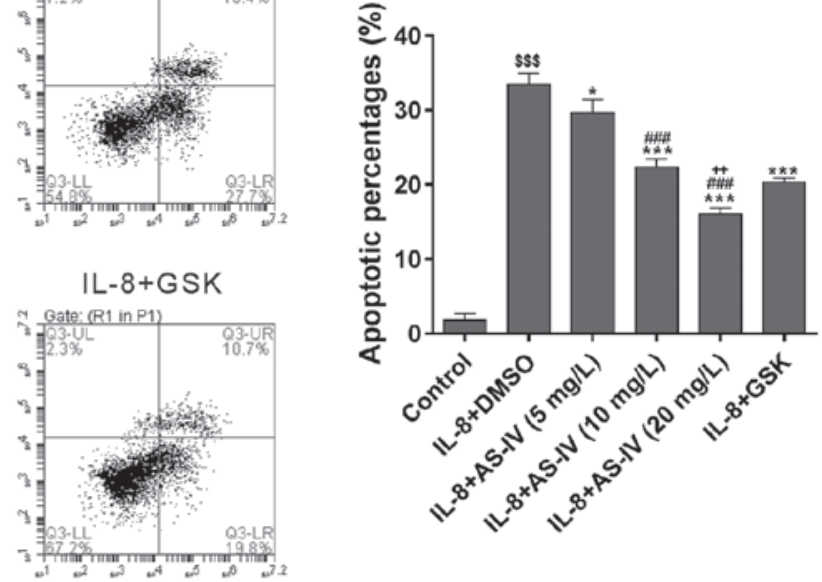

B
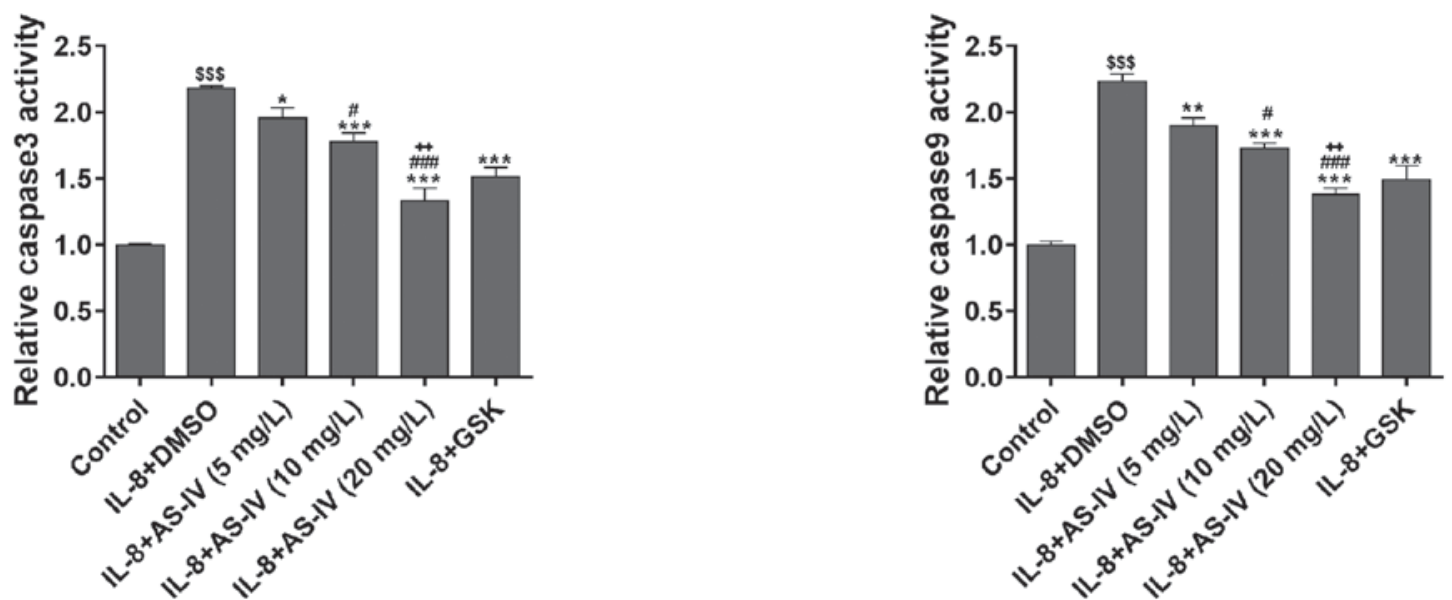

Figure 3. AS-IV attenuates cell apoptosis induced by IL-8. (A) Diaphragmatic muscle cells were treated as indicated for $48 \mathrm{~h}$ and then collected for annexin $\mathrm{V} /$ propidium iodide staining and flow cytometric analysis. Cells in the lower right quadrant and the upper right quadrant underwent early and late apoptosis, respectively. (B) The caspase 3 and caspase 9 activities were detected using a caspase colorimetric assay kit. ${ }^{\$ \$} \mathrm{P}<0.001$ vs. Control; ${ }^{*} \mathrm{P}<0.05,{ }^{* *} \mathrm{P}<0.01$, ${ }^{* * * *} \mathrm{P}<0.001$, vs. IL-8 plus DMSO; ${ }^{\#} \mathrm{P}<0.05,{ }^{\# \# \#} \mathrm{P}<0.001$, vs. IL-8 plus $5 \mathrm{mg} / 1 \mathrm{AS}-\mathrm{IV} ;{ }^{++} \mathrm{P}<0.01$, vs. IL-8 plus $10 \mathrm{mg} / 1 \mathrm{AS}-\mathrm{IV}$. IL, interleukin; AS-IV, astragaloside IV; DMSO, dimethyl sulfoxide; GSK, GSK690693; UR, upper right; LR, lower right; UL, upper left; LL, lower left; Q, quadrant.

Effect of AS-IV on IL-8-induced pro-inflammatory factor production. The concentrations of the pro-inflammatory factors TNF- $\alpha$, IL- 6 and IL- 8 in the culture medium were determined using ELISA (Fig. 5). IL-8 treatment significantly increased the concentrations of these 3 pro-inflammatory factors. The concentrations were significantly suppressed by additional treatment with GSK690693 and AS-IV, respectively.

\section{Discussion}

COPD is a progressive and inflammatory disease that includes the sequela of airflow obstruction. COPD is usually accompanied by breathlessness and fatigue, and eventual respiratory failure from the effects of repeated infections and oxygen deficits (1). As the most important respiratory muscle, the diaphragm is responsible for $\sim 75 \%$ of the mechanical function that occurs during respiration. Damage of the function of the diaphragm has a key role in the induction of respiratory failure (2). Overproduction of ROS induces apoptosis of diaphragmatic muscle cells, which results in diaphragm fatigue (17). In the present study, rat diaphragmatic muscle cells treated with IL-8 were used as a model of inflammation. The significantly increased ROS production accompanied by an increased apoptotic rate indicated that ROS overproduction and diaphragmatic fatigue were associated with the pathogenesis of respiratory failure.

The pharmacological properties of AS-IV have recently gained the attention of researchers (9). Studies have revealed the anti-oxidant and anti-apoptotic functions of AS-IV in various tissue and cell types (13). Inhibition of ROS production was reported to ameliorate monocyte apoptosis $(8,18)$. The inhibitory effect of AS-IV on oxidative stress was demonstrated to contribute to the prevention of acute kidney damage (19). A previous study revealed the critical roles of 

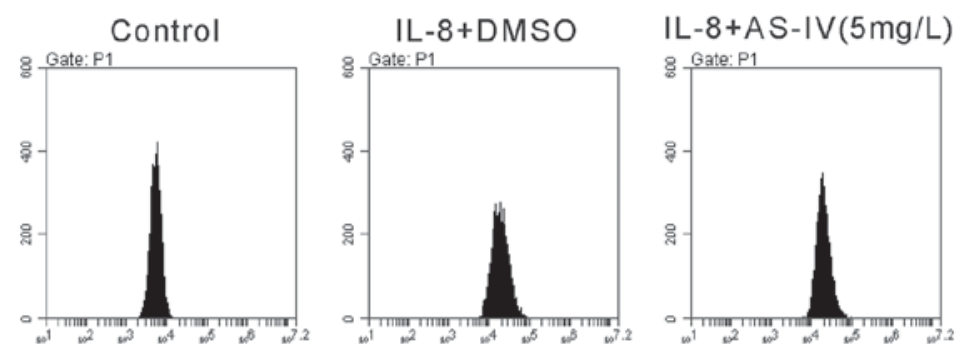

IL-8+AS-IV(10mg/L) IL-8+AS-IV(20mg/L)
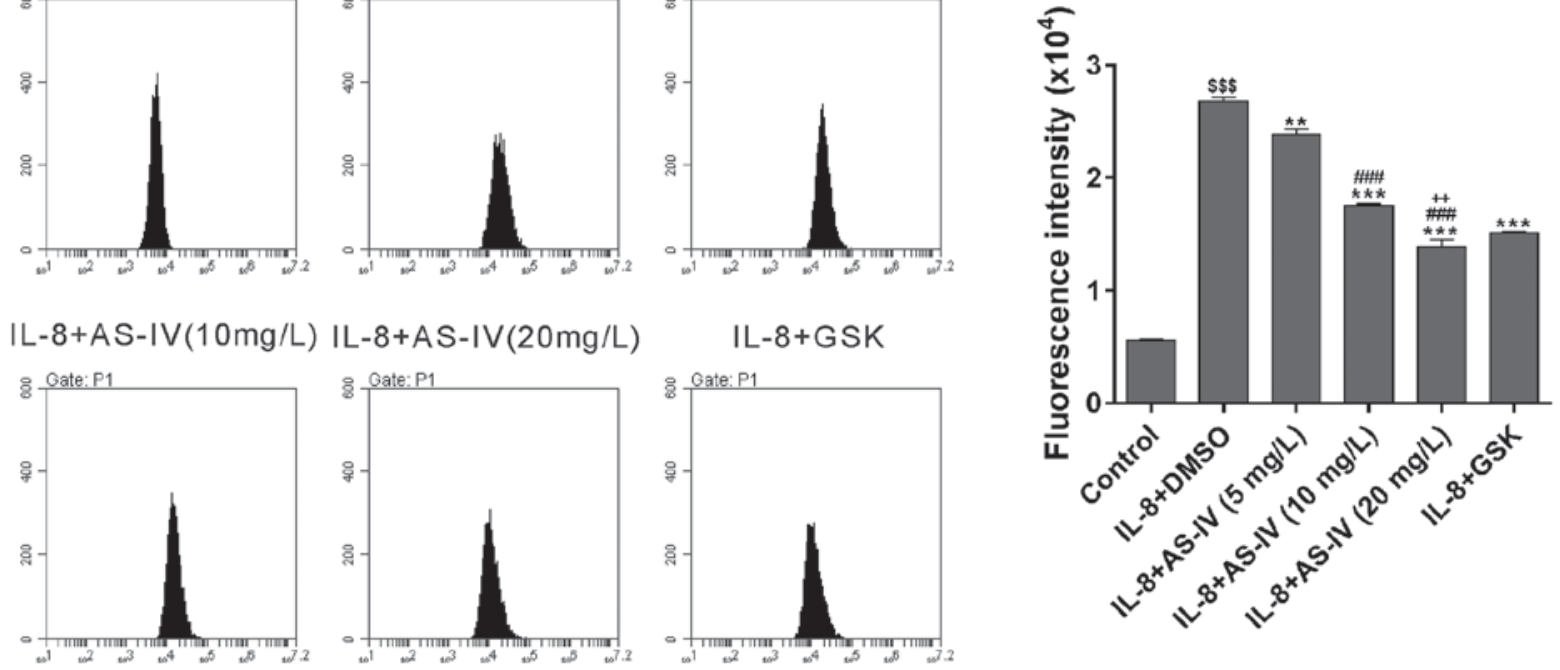

Figure 4. AS-IV attenuates ROS generation induced by IL-8. ROS generation was measured using dichloro-dihydro-fluorescein diacetate labeling and flow cytometric analysis. The cells were pre-gated according the forward scatter (FSC) and side scatter (SSC). ${ }^{\$ \$ \$} \mathrm{P}<0.001$ vs. Control; ${ }^{* * *} \mathrm{P}<0.01,{ }^{* * *} \mathrm{P}<0.001$, vs. IL-8 plus DMSO; ${ }^{\# \# \# ~} \mathrm{P}<0.001$, vs. IL-8 plus $5 \mathrm{mg} / 1$ AS-IV; ${ }^{++} \mathrm{P}<0.01$, vs. IL-8 plus $10 \mathrm{mg} / \mathrm{l}$ AS-IV. ROS, reactive oxygen species; IL, interleukin; AS-IV, astragaloside IV; DMSO, dimethyl sulfoxide; GSK, GSK690693.

A

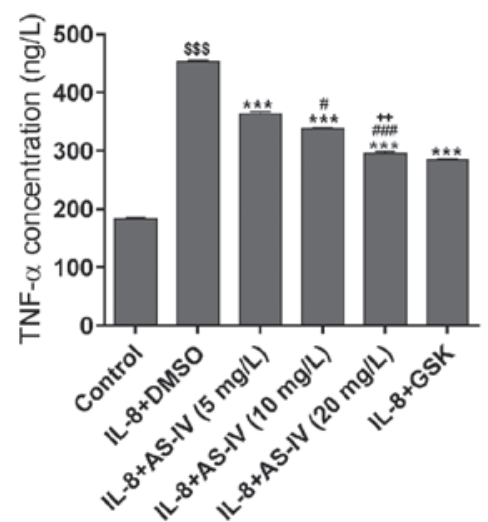

B

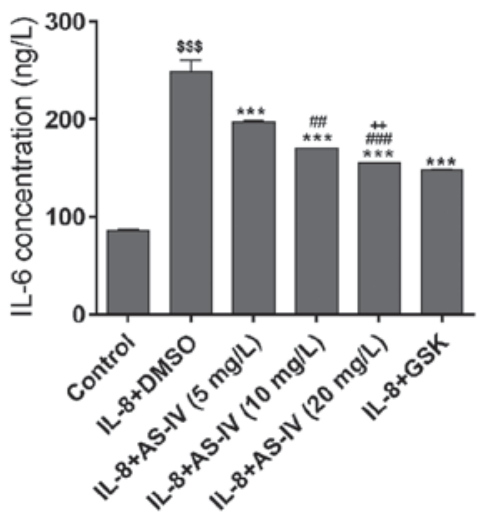

C

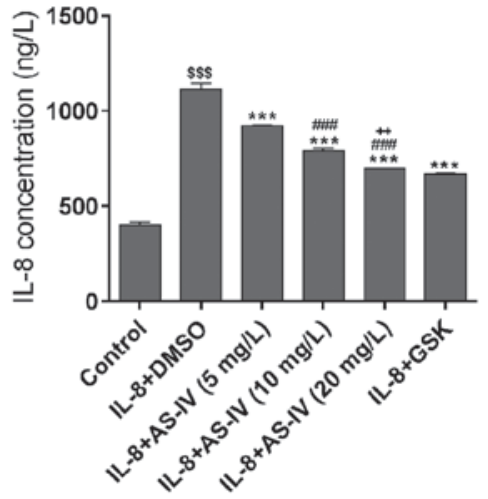

Figure 5. AS-IV suppresses the IL-8-induced inflammatory response. Reduced concentrations of the proinflammatory factors (A) TNF- $\alpha$, (B) IL-6 and (C) IL-8 were detected using ELISA. ${ }^{\$ \$} \mathrm{P}<0.001$ vs. Control; ${ }^{* * *} \mathrm{P}<0.001$, vs. IL-8 plus DMSO; ${ }^{\#} \mathrm{P}<0.05$, ${ }^{\# \#} \mathrm{P}<0.01,{ }^{\# \#} \mathrm{P}<0.001$, vs. IL-8 plus 5 mg/1 AS-IV; ${ }^{++} \mathrm{P}<0.01$, vs. IL-8 plus 10 mg/l AS-IV. IL, interleukin; AS-IV, astragaloside IV; DMSO, dimethyl sulfoxide; GSK, GSK690693; TNF, tumor necrosis factor.

oxidative stress and apoptosis in the pathogenesis of diaphragmatic fatigue (6). Based on the above results, the present study was designed to investigate the protective effects of AS-IV on diaphragmatic muscle cells and examine the associated mechanisms. The results indicated that AS-IV and anti-oxidants including N-acetyl-l-cysteine (NAC) and catalase (results not shown) attenuated the anti-proliferative effects of IL-8 on diaphragmatic muscle cells. Flow cytometric analysis revealed that treatment with AS-IV suppressed the apoptosis and ROS generation induced by IL- 8 in diaphragmatic muscle cells. Caspase-9, an initiator caspase, and caspase-3, an effector caspase, have direct roles in the apoptotic pathway (22). The changes in caspase- 3 and caspase- 9 activities determined in the study were consistent with the flow cytometric results. Treatment with NAC and catalase also suppressed cell apoptosis and ROS generation (results not shown). In the IL-8 plus AS-IV-treated cells, reductions in the pro-inflammatory cytokines IL-6, IL-8 and TNF- $\alpha$ were observed compared with those in the IL-8-treated cells. This result indicated that the inflammatory response in the diaphragmatic muscle cells was inhibited. Taken together, these results indicated that AS-IV had anti-oxidant, anti-apoptotic and anti-inflammatory effects. These results were consistent with those of other studies (10-14).

The AKT pathway contributes to key biological processes, including cell proliferation, apoptosis and inflammation (9). The effects of AS-IV on the AKT pathway have been investigated in human umbilical vein endothelial cells and cardiomyocytes $(19,20)$. The results of the present study indicated that the level of phosphorylation of AKT was increased in IL-8-treated diaphragmatic muscle cells; this response was markedly attenuated by AS-IV and the AKT inhibitor 
GSK690693, respectively. The present results suggested that the AKT pathway is involved in the protective role of AS-IV in diaphragmatic muscle cells.

In conclusion, the present study indicated that the inflammatory diaphragmatic muscle cells induced by IL- 8 had increased rates of AKT phosphorylation, reduced cell proliferation, and increased apoptosis and ROS production. AS-IV exerted anti-oxidant, anti-apoptotic and anti-inflammatory effects to attenuate the effects of IL-8. Additional animal experiments should be performed to further explore this, as the present study suggests that AS-IV may be used for the treatment of diaphragmatic fatigue.

\section{Acknowledgements}

This study was supported by the Science and Technology Projects of Nanjing (grant no. 201605029).

\section{Competing interests}

The authors declare that they have no competing interests.

\section{References}

1. Ni Y, Shi G, Yu Y,Hao J, Chen T and Song H: Clinical characteristics of patients with chronic obstructive pulmonary disease with comorbid bronchiectasis: A systemic review and meta-analysis. Int J Chron Obstruct Pulmon Dis 28: 1465-1475, 2015.

2. Smith-Blair N: Mechanisms of diaphragm fatigue. AACN Clin Issues 13: 307-319, 2002.

3. Demedts IK, Demoor T, Bracke KR, Joos GF and Brusselle GG: Role of apoptosis in the pathogenesis of COPD and pulmonary emphysema. Respir Res 7: 53, 2006.

4. Kirkham PA and Barnes PJ: Oxidative stress in COPD. Chest 144: 266-273, 2013

5. Kyroussis D, Polkey MI, Keilty SE, Mills GH, Hamnegard CH, Moxham J and Green M: Exhaustive exercise slows inspiratory muscle relaxation rate in chronic obstructive pulmonary disease. Am J Respir Crit Care Med 153: 787-793, 1996.

6. Mador MJ, Kufel TJ, Pineda LA and Sharma GK: Diaphragmatic fatigue and high-intensity exercise in patients with chronic obstructive pulmonary disease. Am J Respir Crit Care Med 161: $118-123,2000$.

7. Reid MB: Free radicals and muscle fatigue: Of ROS, canaries, and the IOC. Free Radic Biol Med 44: 169-179, 2008.

8. Keatings VM, Collins PD, Scott DM and Barnes PJ: Differences in interleukin-8 and tumor necrosis factor-alpha in induced sputum from patients with chronic obstructive pulmonary disease or asthma. Am J Respir Crit Care Med 153: 530-534, 1996.
9. Bozinovski S, Vlahos R, Hansen M, Liu K and Anderson GP: Akt in the pathogenesis of COPD. Int J Chron Obstruct Pulmon Dis 1: 31-38, 2006.

10. Cao LL, Li WZ, Si XL, Sun L and Li WP: Protective effect and mechanism of astragaloside IV on oxidative stress injury of mesangial cells. Zhongguo Zhong Yao Za Zhi 38: 725-730, 2013 (In Chinese).

11. Ji KT, Tang JF and Chai JD: Effect of astragaloside against the oxidative damage on endothelial cells. Zhongguo Zhong Xi Yi Jie He Za Zhi 31: 807-810, 2011 (In Chinese).

12. Sun L, Li W, Li W, Xiong L, Li G and Ma R: Astragaloside IV prevents damage to human mesangial cells through the inhibition of the NADPH oxidase/ROS/Akt/NFkappaB pathway under high glucose conditions. Int J Mol Med 34: 167-176, 2014.

13. Zhang A, Zheng Y, Que Z, Zhang L, Lin S, Le V, Liu J and Tian J: Astragaloside IV inhibits progression of lung cancer by mediating immune function of Tregs and CTLs by interfering with IDO. J Cancer Res Clin Oncol 140: 1883-1890, 2014.

14. Qiu YY, Zhu JX, Bian T, Gao F, Qian XF, Du Q, Yuan MY, Sun H, Shi LZ and Yu MH: Protective effects of astragaloside IV against ovalbumin-induced lung inflammation are regulated/mediated by T-bet/GATA-3. Pharmacology 94: 51-59, 2014.

15. Shang L, Qu Z, Sun L, Wang Y, Liu F, Wang S, Gao H and Jiang F: Astragaloside IV inhibits adenovirus replication and apoptosis in A549 cells in vitro. J Pharm Pharmacol 63: 688-694, 2011.

16. Sun J, Chen XL, Zheng JY, Zhou JW and Ma ZL: Astragaloside IV protects new born rats from anesthesia-induced apoptosis in the developing brain. Exp Ther Med 12: 1829-1835, 2016.

17. Hu JY, Han J, Chu ZG, Song HP, Zhang DX, Zhang Q and Huang YS: Astragaloside IV attenuates hypoxia-induced cardiomyocyte damage in rats by upregulating superoxide dismutase-1 levels. Clin Exp Pharmacol Physiol 36: 351-357, 2009.

18. Zhang ZG, Wu L, Wang JL, Yang JD, Zhang J, Zhang J, Li LH, Xia Y, Yao LB, Qin HZ and Gao GD: Astragaloside IV prevents $\mathrm{MPP}^{+}$-induced SH-SY5Y cell death via the inhibition of Bax-mediated pathways and ROS production. Mol Cell Biochem 364: 209-216, 2012.

19. Zhang L, Liu Q, Lu L, Zhao X, Gao X and Wang Y: Astragaloside IV stimulates angiogenesis and increases hypoxia-inducible factor-1 $\alpha$ accumulation via phosphatidylinositol 3-kinase/Akt pathway. J Pharmacol Exp Ther 338: 485-491, 2011.

20. Jia Y, Zuo D, Li Z, Liu H, Dai Z, Cai J, Pang L and Wu Y: Astragaloside IV inhibits doxorubicin-induced cardiomyocyte apoptosis mediated by mitochondrial apoptotic pathway via activating the PI3K/Akt pathway. Chem Pharm Bull (Tokyo) 62: 45-53, 2014.

21. Demoule A, Divangahi M, Danialou G, Gvozdic D, Larkin G, Bao W and Petrof BJ: Expression and regulation of CC class chemokines in the dystrophic (mdx) diaphragm. Am J Respir Cell Mol Biol 33: 178-185, 2005.

22. Elmore S: Apoptosis: A review of programmed cell death. Toxicologic pathology 35: 495-516, 2007. 